Gut, $1971,12,963-967$

\title{
The influence of the individual surgeon and of the type of vagotomy upon the insulin test after vagotomy
}

\author{
DAVID JOHNSTON AND J. C. GOLIGHER \\ From the University Department of Surgery, The General Infirmary, Leeds
}

SUMMARY Six hundred and seventy-six insulin tests performed in the early postoperative period after vagotomy and drainage for duodenal ulcer were analysed by the criteria of Hollander. Consultants had done 364 vagotomies, of which $17.6 \%$ were shown to be incomplete. Registrars and senior registrars had done 312 , of which $12.2 \%$ were incomplete. Thus, consultants may not be significantly better, on average, than their juniors at achieving complete gastric vagotomy, even when allowance is made for the fact that they tend to take on the more difficult cases. The ability to achieve a complete vagotomy varied widely from surgeon to surgeon, regardless of his status.

Of 515 truncal vagotomies, $15.7 \%$ were incomplete compared with $14.3 \%$ of 161 bilateral selective vagotomies. An 'early-positive' secretory response within one hour of the insulin injection, which is commonly regarded as indicating inadequate vagotomy, was found in $5.6 \%$ of patients after truncal vagotomy and $3.1 \%$ of patients after selective vagotomy.

A partial gastrectomy is a partial gastrectomy is a partial gastrectomy, as the resected specimen proves. But a 'vagotomy' is not necessarily a vagotomy, and is certainly not a complete gastric vagotomy in $20 \%$ of cases (Fawcett, Johnston, and Duthie, 1969). That is why there are more recurrent ulcers after vagotomy than after partial gastrectomy for duodenal ulcer.

The individual surgeon might well be expected to perform fewer and fewer incomplete vagotomies as his surgical experience increases. Consultants should thus be better vagotomists than their senior registrars or registrars. This hypothesis was tested in a study of 676 insulin tests performed during the early postoperative period in patients who had undergone truncal or bilateral selective vagotomy with drainage for duodenal ulcer.

Another question examined was whether selective vagotomy denervates the stomach more effectively than does truncal vagotomy, as Burge (1964), Griffith (1969), Kennedy and Connell (1969), and others have claimed.

\section{Method}

The 676 insulin tests were performed over a five-year Received for publication 5 October 1971. period, during which, as far as possible, routine testing was carried out in each male patient submitted to elective operation for chronic duodenal ulceration in three surgical units. Elderly or infirm patients and those with cardiovascular disease, diabetes, or epilepsy were excluded. About threequarters of the patients had an insulin test.

Truncal vagotomy was done in 515 patients and in the other 161 patients bilateral selective vagotomy was performed with preservation of the hepatic and coeliac vagal branches. Heinecke-Mikulicz pyloroplasty was added in $90 \%$ of cases and gastrojejunostomy in $10 \%$.

The surgeons comprised nine consultants (professors, readers, senior lecturers, and NHS consultants), nine senior registrars or lecturers, and six registrars. The consultants were all experienced general surgeons with an interest in gastric surgery. The senior registrars had been in that grade for periods ranging from one to five years, and so were moderately experienced. Seven are now consultants. The registrars were members of the hospital rotation scheme, and had limited surgical experience. Many of their vagotomy operations were supervised by consultants or senior registrars, and in general they were operating only on patients who were expected to present no great technical problem. The 
registrars did not perform selective vagotomy. The methods used in the insulin test have been described in detail (Johnston, Thomas, Checketts, and Duthie, 1967). The test was done five to 12 days postoperatively after the patient had fasted overnight. Each test was closely supervised by a member of staff experienced in gastric testing. A nasogastric or gastrostomy tube was used, and the gastric content was aspirated by continuous suction for three hours, with frequent insufflation of air to keep the tube patent. The gastric aspirate was collected into 12 samples, each representing a 15-minute collection period. The volume of each sample was recorded and the acid concentration measured either by automatic titration to $p \mathrm{H} 7$ or to the phenolphthalein end point ( $p \mathrm{H} \mathrm{8}$ ). Soluble insulin in a dose of 0.15 to 0.25 units per $\mathrm{kg}$ was injected intravenously after the first hour. The test was abandoned if resting juice was excessive or if the presence of food residues indicated gastric retention These technical difficulties were found to be minimized if the test was done about the fifth postoperative day, while the patient was still on a semi-liquid diet, or if solid food was withheld entirely from lunch time on the preceding day. The results of the tests were interpreted by the criteria of Hollander (1948). The mean acid concentration of the two consecutive basal samples which gave the highest reading was compared with that of the two consecutive samples after insulin which gave the highest reading. An increase after insulin of 20 m-equiv per litre or more (or of 10 m-equiv per litre if the basal specimens were anacid) denoted a positive response. A positive response in the first hour (Johnston et al, 1967) after insulin was termed 'early positive' (Ross and Kay, 1964) and a positive response in the second hour, 'late positive'.

\section{Results}

\section{EXPERIENCE OF THE SURGEON}

A large variation in the percentage of positive insulin tests was observed within each grade of surgical experience with both the truncal (Fig. 1) and selective (Fig. 2) operations. Consultants fared no better than more junior members of staff (Figs.

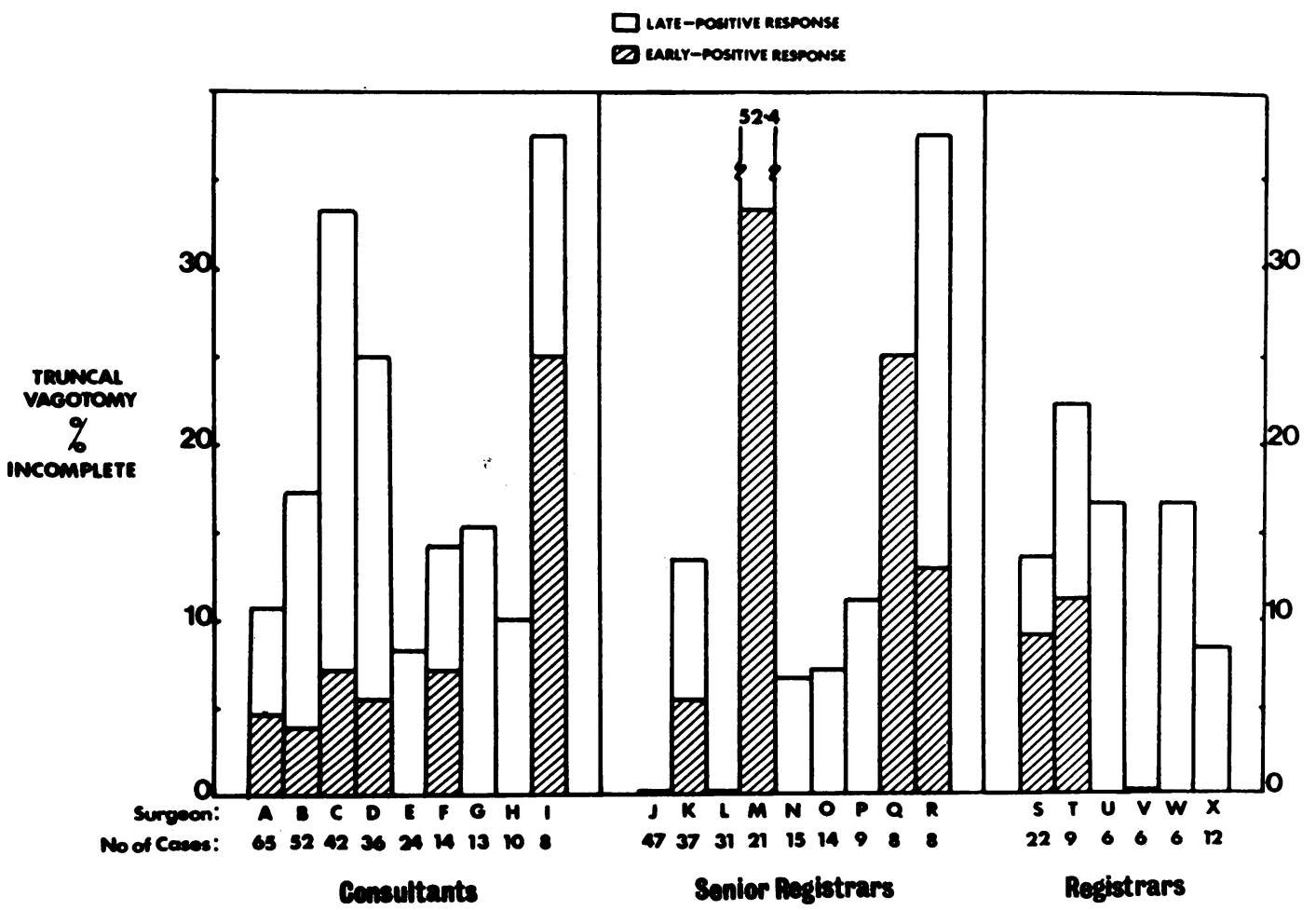

Fig. 1 This shows the great variation in the ability of different surgeons to achieve a complete truncal vagotomy. $J$ and $L$ had no positive insulin tests after 78 vagotomies, whereas more than a third of the vagotomies performed by $C, I, M$, and $R$ were incomplete. 


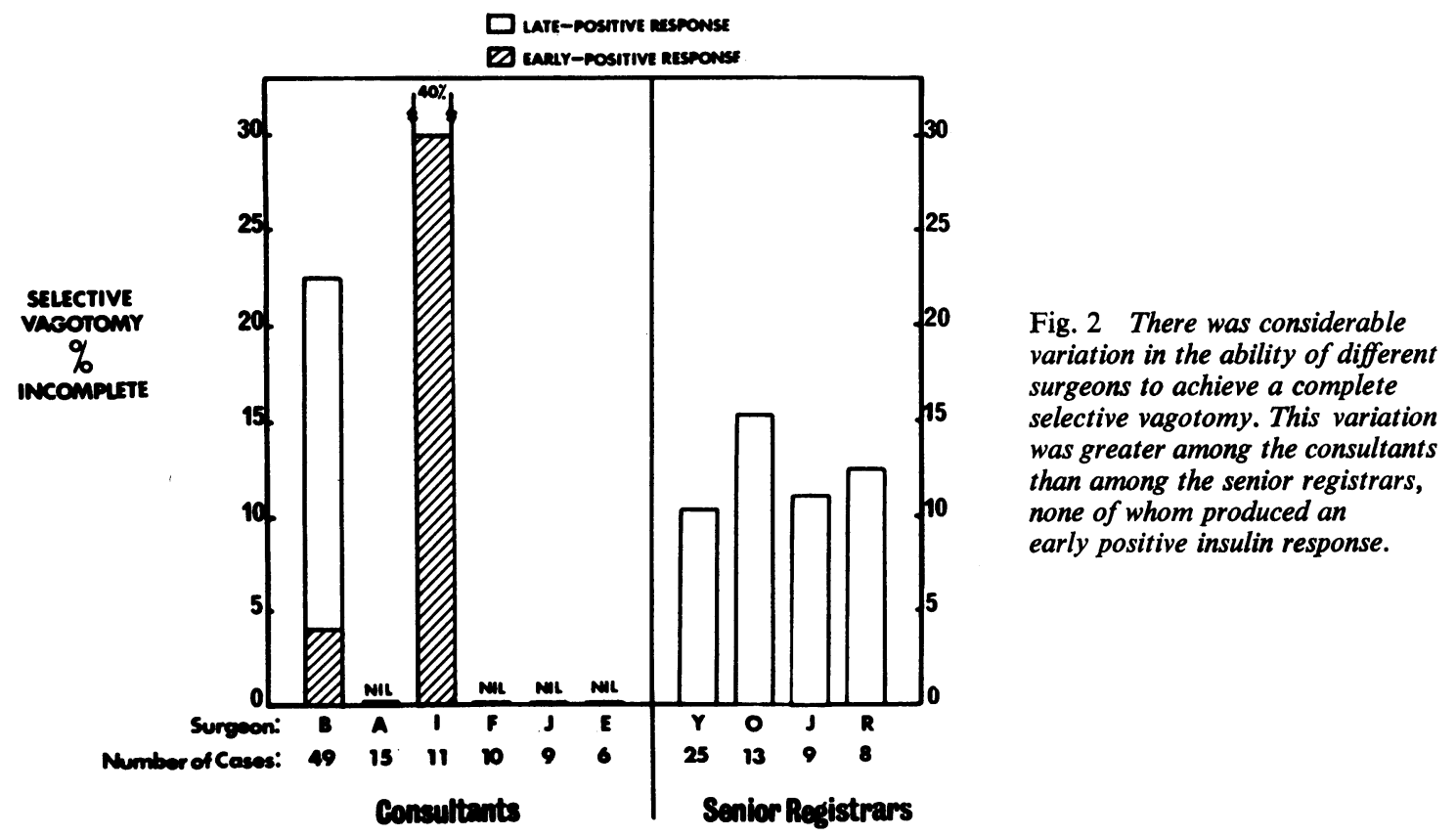

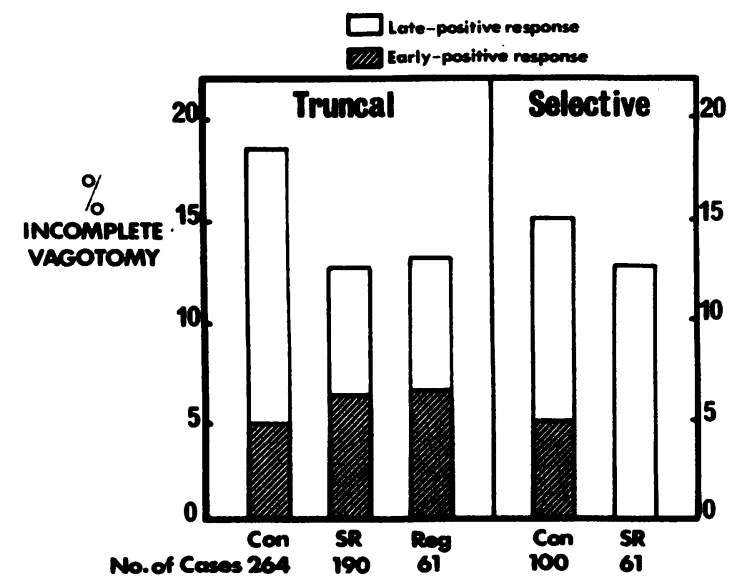

Fig. 3 Incomplete vagotomy was almost as common after selective vagotomy as after truncal vagotomy. Consultants fared no better than registrars in achieving complete gastric vagotomy. 
3 and 4). Of their vagotomies $17.6 \%$ were incomplete compared with $12.2 \%$ of the vagotomies performed by registrars and senior registrars (Fig. 4).

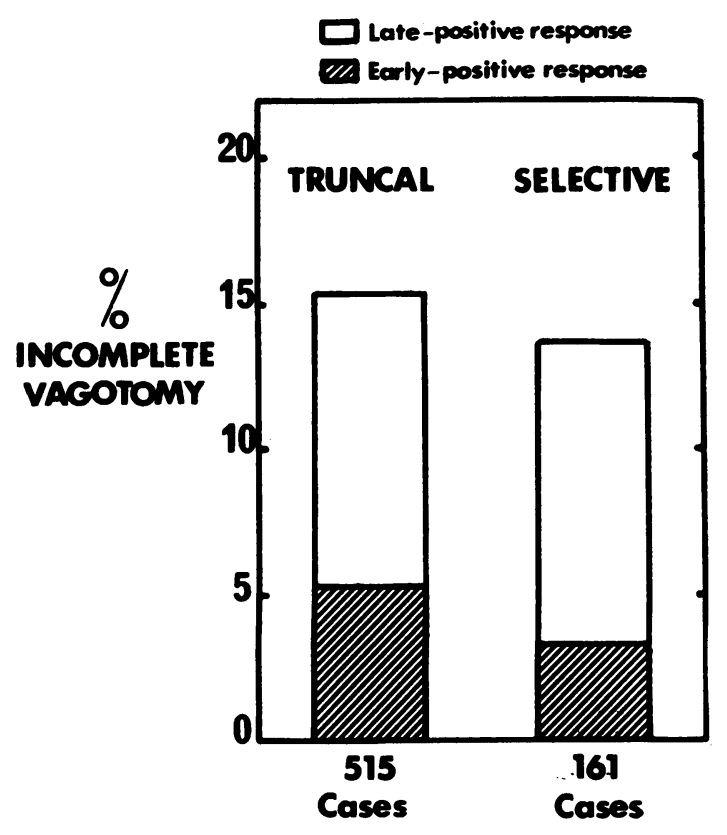

Fig. 5 There was no significant difference between truncal and selective vagotomy with respect to completeness of the gastric vagotomy.

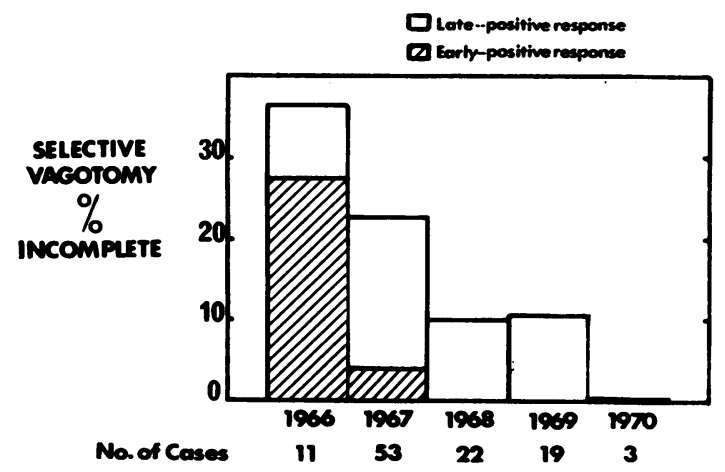

Fig. 6 Year-by-year analysis of the degree of completeness of selective gastric vagotomy on one unit. There appears to have been an 'apprentice' phase in 1966. If the results for 1966 are excluded, the incidence of 'early positive' incomplete vagotomy after selective vagotomy on all three units was two in 150 cases, or $1.3 \%$.
TRUNCAL VERSUS SELECTIVE VAGOTOMY

A positive response to insulin, indicative of an incomplete vagotomy, was found in $15.7 \%$ of 515 patients with truncal vagotomy (Fig. 5): $5.6 \%$ were 'early' positive and $10.1 \%$ 'late' positive. After selective vagotomy, $14.3 \%$ of 161 patients gave a positive response: $3 \cdot 1 \%$ 'early' and $11.2 \%$ 'late'. The difference between truncal and selective vagotomy was not statistically significant.

One hundred and eight of the 161 selective vagotomies were performed on one of the three surgical units. The proportion of patients on that unit shown to have incomplete vagotomy decreased markedly from 1966 to 1968 (Fig. 6). This decrease was most pronounced when early positive responses only were considered. Such a trend was not observed with truncal vagotomy. If the figures for 1966 from that unit are omitted as representing an 'apprentice' phase, the overall incidence of positive insulin tests after selective vagotomy falls to $12.7 \%$ and only two of 150 patients $(1.3 \%)$ had early positive responses. Since patients were not allotted to truncal or selective vagotomy in random manner, the difference between the two types of vagotomy cannot be claimed to be significant.

\section{Discussion}

The results need little comment. Although the hypothesis that consultant surgeons are the best vagotomists is both a plausible and an attractive one-especially to consultant surgeons-the facts are against it. Of course, consultants do take on the more arduous cases, and the good results of the registrars are no doubt attributable to selection for them of slim subjects and to good supervision. Nonetheless, when all possible sources of bias have been taken into account, it is still difficult to avoid the conclusion that the consultants' results are not better than those of their juniors. This is a disappointing finding, and suggests that surgeons who perform vagotomy operations must check on the efficiency of their vagotomies, either at the time of operation (Burge and Vane, 1958; Burge and Frohn, 1969; Grassi, Orecchia, Cantarelli, Fivoli, and Sbuelz, 1969; Grassi, 1971) or by means of postoperative insulin tests. As is seen in Figs. 1 and 2, some surgeons can almost guarantee that their vagotomies will be complete, while others leave 30 , 40 , or even $50 \%$ of their patients with an incomplete vagotomy. Not all of these patients will develop recurrent ulceration, but they are at greater risk of doing so than patients whose vagotomy is complete (Ross and Kay, 1964; Johnston et al, 1967; Fawcett et al, 1969).

Selective vagotomy has been advocated on the 
grounds, inter alia, that it produces a higher percentage of complete gastric vagotomies than does truncal vagotomy (Burge, 1964; Griffith, 1969), and the results of a recent random trial support this contention (Kennedy and Connell, 1969). Our data must be interpreted with caution, because the patients were not randomized between the two types of vagotomy, and thus most of the obese and the high-risk cases were probably treated by truncal vagotomy. Overall, there was little difference between the results after truncal and selective vagotomy, though early positive responses, which are probably indicative of an inadequate vagotomy (Ross and Kay, 1964; Johnston et al, 1967), were more common after truncal than after selective vagotomy.

Many of the insulin tests were performed in the University Department of Surgery at Sheffield Royal Infirmary. We thank Professor H. L. Duthie and $\mathrm{Mr} \mathrm{C}$. H. Talbot for their cooperation, for valuable criticism of the manuscript, and for the facilities and guidance given to one of us (D.J.). We thank also the many doctors and technicians who helped with the insulin testing, especially Mr R. G. Checketts, Mr D. G. Thomas, Mr J. Lari, Mr K. Jepson, Mr M. C. Mason, Dr A. R. Wil- kinson, and Dr C. S. Humphrey. We are indebted to $\mathrm{Mr} \mathrm{R}$. Cree for preparing the figures and to Miss Elaine Bartholomew and Mrs Carole Stenton for typing the manuscript.

References

Burge, H. (1964). In Vagotomy. Arnold, London.

Burge, H., and Vane, J. R. (1958). Method of testing for complete nerve section during vagotomy. Brit. med. J., 1, 615-618.

Burge, H., and Frohn, M. J. N. (1969). The technique of bilateral. selective vagotomy with the electrical stimulation test. Brit. J. Surg., 56, 452-460.

Fawcett, A. N., Johnston, D., and Duthie, H. L. (1969). Revagotomy for recurrent ulcer after vagotomy and drainage for duodenal ulcer. Brit. J. Surg., 56, 111-116.

Grassi, G. (1971). A new test for complete nerve section during vagotomy. Brit. J. Surg., 58, 187-189.

Grassi, G., Orecchia, C., Cantarelli, I., Fivoli, E., and Sbuelz, B. (1969). Risultatie considerazioni sullo studio della secrezione gastrica nella malattia ulcerosa in fase operatoria. Chir. Gastroent., 3, 465-468.

Griffiith, C. A. (1969). In Surgery of the Stomach and Duodenum, 2nd ed., edited by H. N. Harkins and L. M. Nyhus, p. 605 . Little, Brown, Boston.

Hollander, F. (1948). Laboratory procedures in the study of vagotomy with particular reference to the insulin test. Gastroenterology, 11, 419-425.

Johnston, D., Thomas, D. G., Checketts, R. G., and Duthie, H. L. (1967). An assessment of postoperative testing for completeness of vagotomy. Brit. J. Surg., 54, 831-833.

Kennedy, T., and Connell, A. M. (1969). Selective or truncal vagotomy? A double-blind randomised controlled trial. Lancet, 1, 899-901.

Ross, B., and Kay, A. W. (1964). The insulin test after vagotomy. Gastroenterology, 46, 379-386. 